Case Report

\title{
Recurrent Congenital Heart Block Due to Maternal Anti-Ro Antibodies: Successful Prevention of Poor Pregnancy Outcome with Hydroxychloroquine and Added Dexamethasone
}

\author{
Brindusa Cimpoca-Raptis ${ }^{1,2,+}$, Anca Marina Ciobanu ${ }^{1,2, *,+}$, Nicolae Gica 1,2,+(D), Ana Maria Scutelnicu ${ }^{2}$, \\ Alexandra Bouariu ${ }^{2}$, Mihaela Popescu 1,3,*DiD and Anca Maria Panaitescu 1,2, (D) $^{-}$ \\ 1 Department of Obstetrics and Gynecology, Carol Davila University, 020021 Bucharest, Romania; \\ brindusa.cimpoca@gmail.com (B.C.-R.); gica.nicolae@umfcd.ro (N.G.); anca.panaitescu@umfcd.ro (A.M.P.) \\ 2 Filantropia Clinical Hospital, 011171 Bucharest, Romania; ana.scutelnicu@yahoo.com (A.M.S.); \\ alexandra.bouariu@yahoo.com (A.B.) \\ 3 Cardiology Department, Elias University Hospital, 011461 Bucharest, Romania \\ * Correspondence: ciobanu.ancamarina@gmail.com (A.M.C.); roxana.popescu@umfcd.ro (M.P.) \\ + These authors contributed equally to this work.
}

check for updates

Citation: Cimpoca-Raptis, B.; Ciobanu, A.M.; Gica, N.; Scutelnicu, A.M.; Bouariu, A.; Popescu, M.; Panaitescu, A.M. Recurrent Congenital Heart Block Due to Maternal Anti-Ro Antibodies: Successful Prevention of Poor Pregnancy Outcome with Hydroxychloroquine and Added Dexamethasone. Reprod. Med. 2022, 3, 36-41. https://doi.org/10.3390/ reprodmed3010004

Academic Editor: Berthold Huppertz

Received: 6 January 2022 Accepted: 11 February 2022 Published: 14 February 2022

Publisher's Note: MDPI stays neutral with regard to jurisdictional claims in published maps and institutional affiliations.

Copyright: (C) 2022 by the authors. Licensee MDPI, Basel, Switzerland. This article is an open access article distributed under the terms and conditions of the Creative Commons Attribution (CC BY) license (https:// creativecommons.org/licenses/by/ $4.0 /)$

\begin{abstract}
Autoimmune Congenital Heart Block ( $\mathrm{CHB})$ is an immune-mediated disease caused by transplacental passage of maternal circulating anti-Ro/SSA and anti-La/SSB antibodies which can bind to fetal cardiac tissue, damaging conduction tissues by inflammation and fibrosis. Approximately $2 \%$ of pregnancies with positive anti-Ro antibodies will be complicated by fetal atrioventricular block and the risk of recurrence in subsequent pregnancies is 10 times higher. We report a case of a clinically asymptomatic patient diagnosed with anti-Ro antibodies who had two pregnancies complicated by $\mathrm{CHB}$ with different outcomes. Despite preventive treatment with hydroxychloroquine (HCQ) from 6 weeks of pregnancy onward, the fetus developed second to third degree CHB. Dexamethasone was added. The pregnancy evolved to near-term with persistent intermittent $\mathrm{CHB}$. It is not clear how pregnancies with recurrent fetal CHB despite prophylaxis with HCQ should be managed and there is a need for controlled studies to answer the remaining questions in relation to this subject.
\end{abstract}

Keywords: anti-Ro antibodies; congenital heart block; transplacental antibodies passage; hydroxychloroquine

\section{Introduction}

Autoimmune-mediated congenital heart block (CHB), caused in the majority of cases by the transplacental passage of Anti-Ro/Anti-La maternal antibodies, is relatively rare, affecting 1 in 20,000 live births; however, it has a high mortality rate, up to $20 \%$ and a high morbidity rate, requiring a pacemaker implantation in most of the cases [1]. Anti-Ro/La antibodies are present in the context of some autoimmune maternal diseases, mostly related to Sjogren's syndrome (SS) and systemic lupus erythematosus (SLE) but can be present in $2-3 \%$ of healthy, asymptomatic women and are therefore first detected during a pregnancy complicated by CHB [2-4]. These antibodies cause inflammation and fibrosis in the fetal cardiac muscles and atrioventricular (AV) conduction system, causing various degrees of AV block: from first-degree block, which is a benign ECG finding, being found also in 6\% of normal neonates, to the most severe, irreversible form, the third degree (complete) AV block. Complete AV block leads to complete dissociation of the atrial and ventricular activity as a result of the damage in the AV conduction pathways. In patients with third-degree AV block the atrial frequency is in the normal range, but the ventricular rate can be lower than 50 beats per minute, usually between 50 and 80 beats/minute. Anti-Ro/Anti-La can also cause endocardial fibroelastosis. The ultrasound findings in fetal life include ventricular dilatation, reduced ejection fraction, echogenic endocardium located in the left ventricle affecting the mitral valve papillary muscles, and AV valve causing valve dysfunction [5]. 


\section{Case Report}

We present a case of a 30-year-old G2 P2 patient diagnosed in her first pregnancy with Sjogren's syndrome with positive anti-Ro antibodies after the fetal ultrasound revealed heart block and cardiofibroelastosis. Unfortunately, her first pregnancy ended up in fetal intrauterine death at 23 weeks due to progressive fetal hydrops and heart failure caused by the CHB following the transplacental passage of maternal anti-Ro antibodies.

In her second pregnancy, prophylactic hydroxychloroquine (HCQ) was initiated after pregnancy confirmation at 6 weeks gestation. First trimester ultrasound evaluation was normal, and the screening test used for detection of common aneuploidies showed low risk. Regular weekly follow-up scans were offered starting from 16 weeks. Unfortunately, recurrent intermittent 2nd/3rd degree atrio-ventricular block was detected at 22 weeks. (Figure 1A,B) Fetal echocardiography revealed intermittent fetal bradycardia with ventricular rate ranging from 80 beats/minute to short periods of normal frequency of 120-130 beats/minute. No fetal structural abnormalities were identified during ultrasound evaluation. There were no signs of cardiac insufficiency or fibroelastosis and ventricular contractility was normal. Following the diagnosis of intermittent fetal heart block, dexamethasone $4 \mathrm{mg}$ daily was administered up to delivery. The pregnancy continued uneventfully with stable incomplete fetal heart block and moderate bradycardia with a fetal heart rate maintained around 80-100 bpm. (Figure 1C,D) Intermittent, short periods of normal atrioventricular conduction and normal heart rate were recorded throughout gestation. The fetal growth, doppler studies, and amniotic fluid remained normal.
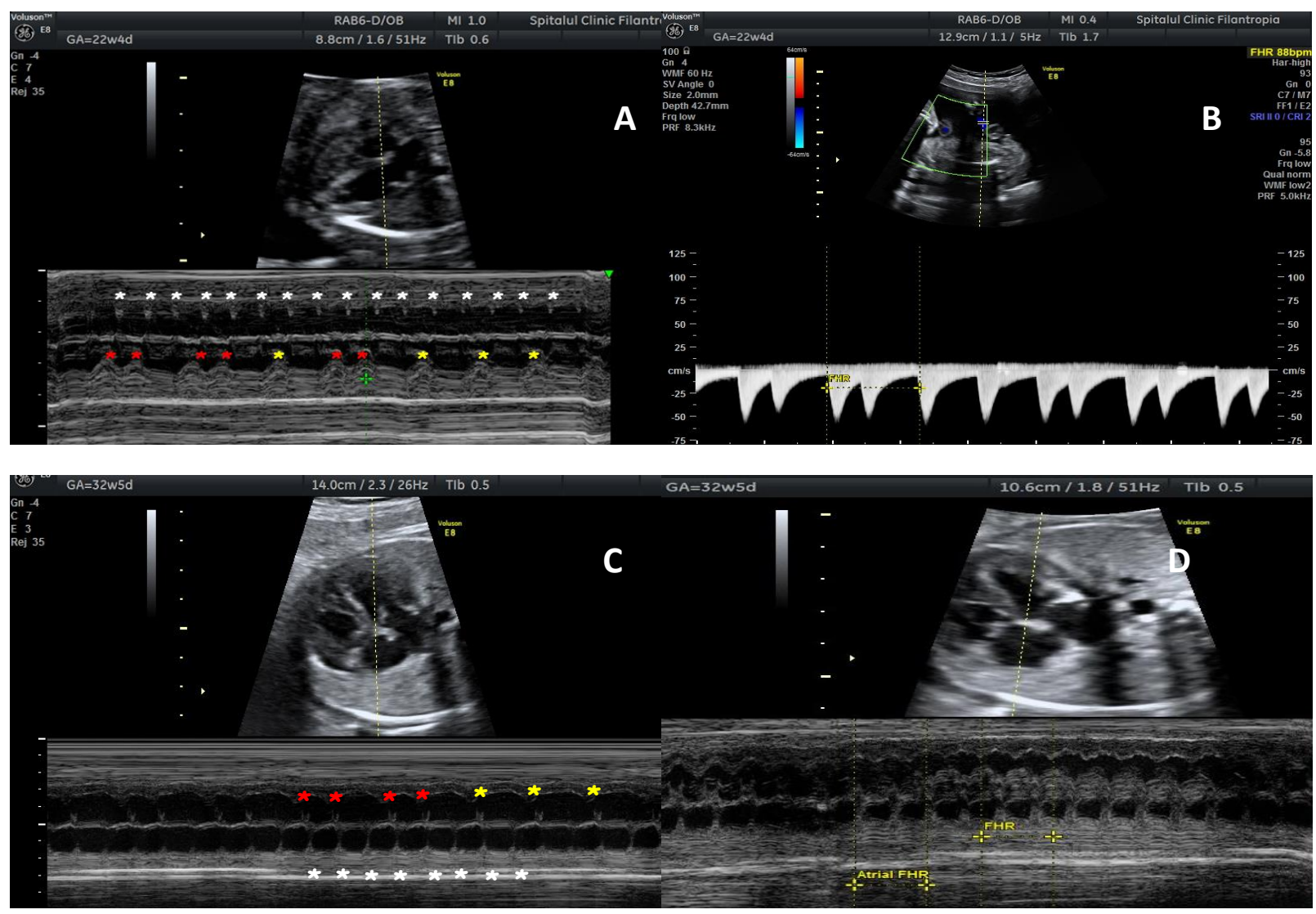

Figure 1. M-mode recording and dopler studies in a fetus with congenital heart block. (A) M-mode fetal echocardiography showing simultaneously atrial contractions (white stars) and ventricular contractions (red stars in 2nd degree block and yellow stars show complete dissociation in 3rd degree block). (B) Umbilical artery power Doppler evaluation shows an incomplete heart block, in intermittent 2nd degree block, heart rate of about 90 bpm. (C,D) M-mode recording 1:1 atrioventricular transmission and normal ventricular rate. 
A live baby of $2600 \mathrm{~g}$ was born at 36 weeks of gestation by caesarean section after preterm rupture of membrane, with Apgar score of 8 at $1 \mathrm{~min}, 9$ at $5 \mathrm{~min}$. After delivery neonatal electrocardiogram confirmed the diagnosis of third-degree AV block, with a ventricular rate of 80 beats/minute and a normal atrial rate of 130 beats/minute. The neonatal echocardiography showed normal cardiac anatomy with normal contractility and mild pericardial effusion. Subsequent neonatal blood tests were performed, and all results were normal, except for positive anti-Ro antibodies. Treatment for this baby included steroids, immunoglobulin, isoprenaline and diuretic. The 5 months follow-up showed no signs of ventricular dysfunction and there was no need for a pacemaker implantation.

\section{Discussion}

Transplacental immunoglobulin G (IgG) passage is an important mechanism in neonatal passive immunity and protection in the first weeks of life, however there are some harmful antibodies linked to autoimmune maternal disease that are able to cross the placenta and affect the unborn baby [6]. Among such harmful antibodies for the fetus are anti-Ro antibodies, initially described in association with SLE or/and SS, but also in completely asymptomatic women [7].

Neonatal lupus is a passively acquired autoimmune disorder caused by transplacental passage of maternal anti-Ro/anti-La antibodies. This condition can cause cutaneous, hematologic or cardiac manifestations. The life-threatening complication is fetal complete atrioventricular block, which occurs in $2 \%$ of nulliparous women positive for anti-Ro antibodies, but the risk increases up to $20 \%$ in pregnancies with a previously affected fetus $[1,8]$.

The transplacental transfer of these antibodies starts in the early second trimester, and the greatest risk for $\mathrm{CHB}$ is between 16 and 28 weeks of gestation. The pathophysiology of the fetal congenital heart block is related to inflammation and fibrosis of the atrioventricular node. The risk of death amongst affected fetuses is about $15-20 \%$ and the predictors for a poor prognosis and mortality are fetal hydrops, severe cardiac fibroelastosis, dilated cardiomyopathy, valvular dysfunction, and a very low heart rate [8-10].

As soon as the first- or second-degree block is identified after birth, intensive monitoring of these newborns is required, as there is a risk of postnatal progression to third-degree block [11]. Infants born with complete heart block and heart rates under 55 beats/minute require implantation of a cardiac pacemaker. Some of the babies that are asymptomatic at birth end up also requiring a pacemaker later, mostly during childhood or adolescence [8-10].

The case presented in this paper was completely asymptomatic in their first pregnancy and was referred to our unit at 23 weeks of gestation due to abnormal fetal heart rhythm at the routine anomaly scan. The diagnosis of a third-degree AV fetal block was made. Further findings were observed, including dilated and dysfunctional ventricles and unfortunately, fetal hydrops. Maternal laboratory tests revealed positive antinuclear antibodies and high titers of anti-Ro ( $>200 \mathrm{UI} / \mathrm{L}$ ). Schirmer test diagnosed severe eye dryness $(4 \mathrm{~mm}$ for the left eye and $5 \mathrm{~mm}$ for the right eye). In addition, there were suggestive ultrasound changes in the parotid glands. Following these investigations, the diagnosis of SS was made. Unfortunately, the pregnancy ended in an intrauterine death at 23 weeks.

Knowing the maternal diagnosis and her previous history, once the second pregnancy was confirmed the patient started prophylactic hydroxychloroquine treatment. The couple was counseled regarding the high risk of recurrence of complete fetal heart block and weekly fetal echocardiography was offered from 16 weeks of gestation, as the most vulnerable period of poor fetal outcome is 16 to 28 weeks of gestation.

The development of $\mathrm{CHB}$ can sometimes be unpredictable as it does not follow the standard disease progression and the duration of progression can also sometimes be unpredictable. Third degree $\mathrm{CHB}$ can be a transition from normal sinus rhythm within $24 \mathrm{~h}$ [11]. PRIDE study recommends weekly fetal heart scan in order to assess signs of cardiac damage such as pericardial effusion, left ventricular enlargement or poor contraction, 
AV valve regurgitation or hydrops fetalis [12], however, this approach is controversial and not supported by all [13].

Prevention options for patients with previously affected babies are summarized in Table 1. Hydroxychloroquine inhibits Toll-like receptor signaling and is currently recommended to all pregnant women who previously had a child with cardiac manifestations of neonatal lupus and who are positive for anti-Ro/SSA and/or anti-LA/SSB antibodies, regardless of maternal clinical manifestations. For maximal effect prophylactic treatment should be started early in the first trimester or continued throughout pregnancy for patients who are already on this medication [14].

According to the first prospective study investigating the efficiency of oral $\mathrm{HCQ}$, PATCH trial, the recurrence risk of fetal heart block is halved from $18 \%$ to $7.4 \%$ when $400 \mathrm{mg} \mathrm{HCQ}$ is initiated by 10 weeks and maintained throughout gestation [15]. In this trial, recurrence was defined as a repeated 2nd or 3rd degree block, but not 1st degree block or mild isolated endocardial fibroelastosis. Izmirly et al. notes that if the patient is already on $200 \mathrm{mg}$ of HCQ, the dose should be increased to $400 \mathrm{mg}$ and that treatment should be initiated before completion of 11 weeks [16].

Recently published data highlights the safety of the use of HCQ during pregnancy. Friedman et al. show no correlation between cord blood levels of HCQ and neonatal corrected QT interval (QTc) after analyzing 45 neonatal ECGs $(\mathrm{R}=0.02, p=0.86)$. Only 5 neonates in Friedman's study, $11 \%$ of the population had prolonged QTc above 2 SD when compared with historical healthy controls but ECGs were otherwise unremarkable [17].

In 2010, Preventive IVIG Therapy for Congenital Heart Block (PITCH) study was published aiming to investigate the use of intravenous immunoglobulin in preventing fetal heart block in mothers with anti-SSA/Ro positive antibodies and a previously affected baby (CHB or neonatal lupus rash) and a first trimester pregnancy with ongoing treatment with at least $20 \mathrm{mg}$ of prednisone [18]. The result of this study demonstrated that intravenous immunoglobulin is ineffective in preventing development of $\mathrm{CHB}$ in pregnancies at risk of CHB recurrence [18]. Therefore, the use of intravenous immunoglobulin aiming to reduce recurrence of fetal heart block is not encouraged. Li Zhao et al. report the case of a successful prevention of fetal heart block using a combination of HCQ, intravenous immunoglobulin and methylprednisolone [19] in an anti-SSA/Ro positive antibodies and antinuclear positive antibodies woman.

Table 1. Prophylactic medication choses for mothers with anti-SSA/Ro positive antibodies and a previously affected baby (Congenital heart block or neonatal lupus rash). HCQ-hydroxychloroquine, $\mathrm{w}$-weeks of gestation, BET, betamethasone; DEX, dexamethasone; CHB Congenital heart block.

\begin{tabular}{ccccc}
\hline Study & Medication & Dosage & Timing & Aim of Treatment \\
\hline PATCH [16] & Oral HCQ & $400 \mathrm{mg}$ & Before completion of 11 weeks & Risk or recurrence halved to 7.4\% \\
\hline PITCH [18] & IVIG Therapy & $400 \mathrm{mg} / \mathrm{kg}$ & $12 \mathrm{w}, 15 \mathrm{w}, 18 \mathrm{w}, 21$ and $24 \mathrm{w}$ & No reduction in recurrence risk \\
\hline Ciardulli [20] & $\begin{array}{c}\text { oral } \\
\text { BET / DEX }\end{array}$ & $4 \mathrm{mg} /$ day & Not reported & $\begin{array}{c}\text { Regression or persistence 2nd degree } \\
\text { immune-mediated CHB }\end{array}$ \\
\hline
\end{tabular}

There are contradictory results regarding the treatment with corticosteroids-fluorinated steroids (FS) - once the 2nd degree heart block was diagnosed as a prevention method to progression to 3rd degree block. Some researchers do not support the use of fluorinated steroids to prevent disease progression in cases presenting with isolated heart block, but some consider that randomized controlled trials are needed before steroids are discouraged [20]. In the presented case, dexamethasone was given until delivery, as there were intermittent periods of normal heart rate with 2 nd and 3rd degree heart block. Fluorinated steroids cross the placenta and are, in theory, an appealing treatment addressing the proposed etiopathogenesis of CHB. It is theorized that CHB develops by inflammation in the fetal conductive system and that sustained inflammation would lead to fibrosis and irreversible complete AV block. Theoretically, FS would interfere with this evolution. In 
practice however, studies have repeatedly shown that FS are not efficacious in preventing $\mathrm{CHB}$ or evolution to complete AV block [21,22]. Moreover, their use is associated with important adverse effects both for the woman and the baby including impaired kidney function with reduced amniotic fluid volume, impaired thyroid function in the fetus, low birth weight, maternal glucose intolerance, anxiety $[23,24]$ and possible negative effects on brain development of the child [24]. In our case, obviously, we cannot tell whether FS added from the moment we discovered the recurrent $\mathrm{CHB}$ had any effect. The treatment option was presented to the parents discussing its limitations and potential adverse effects.

A weekly follow-up with fetal echocardiography to assess the signs of cardiac damage such as pericardial effusion, left ventricular enlargement or poor contraction, AV valve regurgitation or hydrops fetalis was proposed in the PRIDE study [12], however, this approach is not recommended by all [13]. It is not clear how women on HCQ for prevention of a recurrent fetal CHB should be followed, nor is it clear how monitoring should be scheduled once a lesser degree CHB is discovered in spite HCQ treatment.

In the absence of other fetal complications, current guidelines recommend planned delivery around 37 weeks, in specialized centers with appropriate resources for cardiac and neonatal intensive care. In the presented case, delivery occurred at 36 weeks due to ruptured membranes. Abnormal fetal heart rate made heart rate monitoring difficult during labor and therefore a caesarean section was the opted mode of delivery for the presented case.

\section{Conclusions}

Congenital heart block is the most severe consequence of transplacental passage of maternal anti-Ro antibodies which carries a high rate of mortality and morbidity. The most challenging cases are those in completely asymptomatic, apparently healthy mothers. These can be carriers of such antibodies and, unfortunately, the diagnosis is made only upon pregnancy complications. Multidisciplinary approach, involving maternal fetal specialist, rheumatologist, cardiologist, and neonatologist is essential in achieving a fortunate outcome in such pregnancies. Once the mother is identified as being positive for anti-Ro antibodies, close fetal monitoring is recommended to be started at 16 weeks of pregnancy, prophylactic treatment should be initiated as early as possible following pregnancy confirmation. In those cases where despite HCQ treatment, $\mathrm{CHB}$ still occurs, there are no clear data for treatment and monitoring. Controlled studies would be welcome in this population.

Author Contributions: Conceptualization, A.M.P. and A.M.C.; methodology A.M.P. and M.P.; resources N.G., A.M.S. and A.B.; data curation, B.C.-R. and A.B. writing-original draft preparation, A.M.P.; writing-A.M.P. and B.C.-R.; supervision A.M.C.; project administration, A.M.P. and N.G. All authors have read and agreed to the published version of the manuscript.

Funding: This research received no external funding.

Institutional Review Board Statement: The study was conducted according to the guidelines of the Declaration of Helsinki.

Informed Consent Statement: Anonymized patient data were used and no individual informed consent was required.

Conflicts of Interest: The authors declare no conflict of interest.

\section{References}

1. Wainwright, B.; Bhan, R.; Trad, C.; Cohen, R.; Saxena, A.; Buyon, J.; Izmirly, P. Autoimmune-mediated congenital heart block. Best Pract. Res. Clin. Obstet. Gynaecol. 2020, 64, 41-51. [CrossRef]

2. Guo, Y.P.; Wang, C.G.; Liu, X.; Huang, Y.Q.; Guo, D.L.; Jing, X.Z.; Yuan, C.G.; Yang, S.; Liu, J.M.; Han, M.S.; et al. The Prevalence of Antinuclear Antibodies in the General Population of China: A Cross-Sectional Study. Curr. Ther. Res. Clin. Exp. 2014, 76, 116-119. [CrossRef] [PubMed]

3. Satoh, M.; Chan, E.K.; Ho, L.A.; Rose, K.M.; Parks, C.G.; Cohn, R.D.; Jusko, T.A.; Walker, N.J.; Germolec, D.R.; Whitt, I.Z.; et al. Prevalence and sociodemographic correlates of antinuclear antibodies in the United States. Arthritis Rheum. 2012, 64, $2319-2327$. [CrossRef] [PubMed] 
4. Hayashi, N.; Koshiba, M.; Nishimura, K.; Sugiyama, D.; Nakamura, T.; Morinobu, S.; Kawano, S.; Kumagai, S. Prevalence of disease-specific antinuclear antibodies in general population: Estimates from annual physical examinations of residents of a small town over a 5-year period. Mod. Rheumatol. 2008, 18, 153-160. [CrossRef] [PubMed]

5. $\quad$ Nield, L.E.; Smallhorn, J.F.; Benson, L.N.; Hornberger, L.K.; Silverman, E.D.; Taylor, G.P.; Mullen, M.; Brendan, J.; Hornberger, L.K. Endocardial fibroelastosis associated with maternal Anti-Lo and Anti-La antibodies in the absence of atrioventricular block. J. Am. Coll. Cardiol. 2002, 40, 796-802. [CrossRef]

6. Ciobanu, A.M.; Dumitru, A.E.; Gica, N.; Botezatu, R.; Peltecu, G.; Panaitescu, A.M. Benefits and Risks of IgG Transplacental Transfer. Diagnostics 2020, 10, 583. [CrossRef]

7. Popescu, M.R.; Dudu, A.; Jurcut, C.; Ciobanu, A.M.; Zagrean, A.M.; Panaitescu, A.M. A Broader Perspective on Anti-Ro Antibodies and Their Fetal Consequences-A Case Report and Literature Review. Diagnostics 2020, 10, 478. [CrossRef]

8. Panaitescu, A.M.; Nicolaides, K. Maternal autoimmune disorders and fetal defects. J. Matern. Fetal Neonatal Med. 2018, 31, 1798-1806. [CrossRef] [PubMed]

9. $\quad$ Fredi, M.; Andreoli, L.; Bacco, B.; Bertero, T.; Bortoluzzi, A.; Breda, S.; Cappa, V.; Ceccarelli, F.; Cimaz, R.; De Vita, S.; et al. First Report of the Italian Registry on Immune-Mediated Congenital Heart Block (Lu.Ne Registry). Front. Cardiovasc. Med. $2019,28,11$. [CrossRef]

10. Levesque, K.; Morel, N.; Maltret, A.; Baron, G.; Masseau, A.; Orquevaux, P.; Piette, J.C.; Barriere, F.; Le Bidois, J.; Fermont, L.; et al. Description of 214 cases of autoimmune congenital heart block: Results of the French neonatal lupus syndrome. Autoimmun. Rev. 2015, 14, 1154-1160. [CrossRef]

11. Cuneo, B.F.; Ambrose, S.E.; Tworetzky, W. Detection and successful treatment of emergent anti-SSA-mediated fetal atrioventricular block. Am. J. Obstet. Gynecol. 2016, 215, 527-528. [CrossRef]

12. Friedman, D.M.; Kim, M.Y.; Copel, J.A.; Davis, C.; Phoon, C.K.; Glickstein, J.S.; Buyon, J.P. Utility of cardiac monitoring in fetuses at risk for congenital heart block: The PR interval and dexamethasone evaluation (PRIDE) prospective study. Circulation 2008, 117, 485-493. [CrossRef]

13. Hunter, L.E.; Simpson, J.M. Atrioventricular block during fetal life. J. Saudi Heart Assoc. 2015, 27, 164-178. [CrossRef]

14. Moak, J.P.; Barron, K.S.; Hougen, T.J.; Wiles, H.B.; Balaji, S.; Sreeram, N.; Cohen, M.H.; Nordenberg, A.; Van Hare, G.F.; Friedman, R.A.; et al. Congenital heart block: Development of late-onset cardiomyopathy, a previously underappreciated sequela. J. Am. Coll. Cardiol. 2001, 37, 238-242. [CrossRef]

15. Izmirly, P.M.; Costedoat-Chalumeau, N.; Pisoni, C.N.; Khamashta, M.A.; Kim, M.Y.; Saxena, A.; Friedman, D.; Llanos, C.; Piette, J.C.; Buyon, J.P. Maternal use of hydroxychloroquine is associated with a reduced risk of recurrent anti-SSA/ro-antibodyAssociated cardiac manifestations of neonatal lupus. Circulation 2012, 126, 76-82. [CrossRef]

16. Izmirly, P.; Kim, M.; Friedman, D.M.; Costedoat-Chalumeau, N.; Clancy, R.; Copel, J.A.; Phoon, C.K.; Cuneo, B.F.; Cohen, R.E.; Robins, K.; et al. Hydroxychloroquine to Prevent Recurrent Congenital Heart Block in Fetuses of Anti-SSA/Ro-Positive Mothers (PATCH). J. Am. Coll. Cardiol. 2020, 76, 292-302. [CrossRef]

17. Friedman, D.M.; Kim, M.; Costedoat-Chalumeau, N.; Clancy, R.; Copel, J.; Phoon, C.K.; Cuneo, B.F.; Cohen, R.; Masson, M.; Wainwright, B.J.; et al. Electrocardiographic QT Intervals in Infants Exposed to Hydroxychloroquine Throughout Gestation. Circ. Arrhythmia Electrophysiol. 2020, 13, 1-18. [CrossRef]

18. Friedman, D.M.; Llanos, C.; Izmirly, P.M.; Brock, B.; Byron, J.; Copel, J.; Cummiskey, K.; Dooley, M.A.; Foley, J.; Graves, C.; et al. Evaluation of fetuses in a study of intravenous immunoglobulin as preventive therapy for congenital heart block: Results of a multicenter, prospective, open-label clinical trial (PITCH). Arthritis Rheum. 2010, 62, 1138-1146. [CrossRef]

19. Zhao, L.; Zhou, Y.; Wang, C.; Li, Y.; Zhu, Q.; Hua, Y.; Qiao, L.; Wu, J.; Zhou, K. Successful Prevention of Fetal AutoimmuneMediated Heart Block by Combined Therapies with Hydroxychloroquine and Intravenous Immunoglobulin: A Case Report. Front. Cardiovasc. Med. 2021, 8, 1-5. [CrossRef]

20. Ciardulli, A.; D'Antonio, F.; Magro-Malosso, E.R.; Manzoli, L.; Anisman, P.; Saccone, G.; Berghella, V. Maternal steroid therapy for fetuses with second-degree immune-mediated congenital atrioventricular block: A systematic review and meta-analysis. Acta Obstet. Et Gynecol. Scand. 2018, 97, 787-794. [CrossRef]

21. Izmirly, P.M.; Saxena, A.; Sahl, S.K.; Shah, U.; Friedman, D.M.; Kim, M.Y.; Buyon, J.P. Assessment of fluorinated steroids to avert progression and mortality in anti-SSA/Ro-associated cardiac injury limited to the fetal conduction system. Ann. Rheum. Dis. 2016, 75, 1161-1165. [CrossRef]

22. Michael, A.; Radwan, A.A.; Ali, A.K.; Abd-Elkariem, A.Y.; Shazly, S.A. Middle-East Obstetrics and Gynecology Graduate Education (MOGGE) Foundation Research Group.Use of antenatal fluorinated corticosteroids in management of congenital heart block: Systematic review and meta-analysis. Eur. J. Obstet. Gynecol. Reprod. Biol. X 2019, 16, 100072. [CrossRef]

23. Scutelnicu, A.; Panaitescu, A.M.; Ciobanu, A.M.; Gica, N.; Botezatu, R.; Peltecu, G.; Gheorghiu, M.L. Iatrogenic Cushing's syndrome as a consequence of nasal use of Betamethasone spray during pregnancy. Acta Endocrinol. 2020, 16, 511-517. [CrossRef]

24. McCann-Crosby, B.; Placencia, F.; Adeyemi, O.; Dietrich, J.; Wills, R.; Gunn, S.; Axelrad, M.; Tu, D.; Mann, D.; Karaviti, L.; et al. Challenges in Prenatal Treatment with Dexamethasone. Pediatr. Endocrinol. Rev. 2018, 16, 186-193. [CrossRef] 